Article

\title{
Modeling of the Melting of Aluminum Particles during the RH Refining Process
}

\author{
Chang Liu $₫$, Haojian Duan and Lifeng Zhang * \\ School of Metallurgical and Ecological Engineering, University of Science and Technology Beijing (USTB), \\ Beijing 100083, China; liuchang_san@outlook.com (C.L.); duanhaojian@163.com (H.D.) \\ * Correspondence: zhanglifeng@ustb.edu.cn; Tel.: +86-010-6233-2267
}

Received: 28 March 2019; Accepted: 11 April 2019; Published: 15 April 2019

\begin{abstract}
The aluminum content in oriented silicon steel obviously influences its magnetic properties. In the current work, the movement and melting process of added aluminum particles during Ruhrstahl-Heraeus ( $\mathrm{RH})$ treatment were simulated using a mathematical approach, considering the effect of the multiphase fluid flow on the evolution of aluminum particles and the dissolved aluminum distribution. The current model was validated by the [Al] content in the molten steel measured by an industry experiment. Most of the added aluminum particles were melted within $5 \mathrm{~s}$ after they connected with the molten steel under the superheat of $28 \mathrm{~K}$. The statistics of the melting time and trajectory length showed a normal distribution. Furthermore, both the melting time and the trajectory length of aluminum particles decreased as the superheat increased. Since the maximum mixing time may go up when the superheat is excessive, the suggested superheat should range from $20 \mathrm{~K}$ to $30 \mathrm{~K}$ during the $\mathrm{RH}$ refining process. Besides, an appropriate sampling position with a short mixing time was proposed.
\end{abstract}

Keywords: mathematical model; RH treatment; aluminum melting; mixing time; superheat

\section{Introduction}

The Ruhrstahl-Heraeus (RH) refining technology is widely used in the manufacture of ultra-carbon steel, such as Interstitial-Free steel and silicon steel [1-3], which requires exact control of the compositions and properties. Since the aluminum concentration in molten steel has a significant effect on the magnetic property of silicon steels, the aluminum melting and mixing processes are extremely important. Cold aluminum particles are added from the vacuum chamber several times to adjust the composition and the temperature of the molten steel during the $\mathrm{RH}$ treatment. The solid aluminum particles are heated by the molten steel and melted into the molten steel, and the dissolved aluminum then circulates with the turbulent flow in the $\mathrm{RH}$ reactor. The mechanism of the melt of the feeding alloy has been discussed in some previous studies [4-8]. When the $25^{\circ} \mathrm{C}$ alloy makes contact with the high-temperature molten steel, a solidified crust of steel is formed around the alloy particle. Firstly, the diameter of the particle increases and then decreases $[9,10]$. When the steel crust is melted completely due to the heat transfer, the molten aluminum is dissolved and mixed into the molten steel. Recently, the numerical modeling approach has been applied to reveal the interior reaction and transport phenomena, which has the advantages of efficiency and convenience in computation. Thus, following the previous study on the transport phenomena between the alloy and the molten steel, a lot of investigations have been developed to simulate the mixing time of the $\mathrm{RH}$ reactor using the mathematical modeling approach, while few of them consider the effect of the injection process and the melting process [11]. Usually, a certain mass tracer is injected in the molten steel, and the movement of the tracer and the mixing time are then investigated. Actually, plenty of researchers have focused on the simulation of the fluid flow [2,12-14], the chemical reaction [15-17], and the inclusions' behavior [18-20] during the RH 
treatment. However, few previous studies have been concerned with the coupling model of the flow field and the alloy melting process.

In the current study, coupling the aluminum particles' melting process with the multiphase fluid flow, a mathematical model including the feeding process of aluminum particles was developed to investigate the melting and the mixing process during the $\mathrm{RH}$ degassing process. Moreover, the influence of superheat on the aluminum evolution was investigated and the optimized superheat range was obtained.

\section{Mathematical Model}

\subsection{Multiphase Fluid Flow}

The coupled volume of the fluid and discrete phase model is employed to simulate the flow field during the RH treatment, and the turbulent features are solved by the $k-\varepsilon$ model. Detailed information on the multiphase fluid flow simulation, including the mesh and the solution method, can be found in references [21,22]. Figure 1 shows the fluid flow simulation results based on the above mathematical model. The molten steel circulates among the ladle and the vacuum chamber accompanied by the mass transfer of dissolved aluminum.

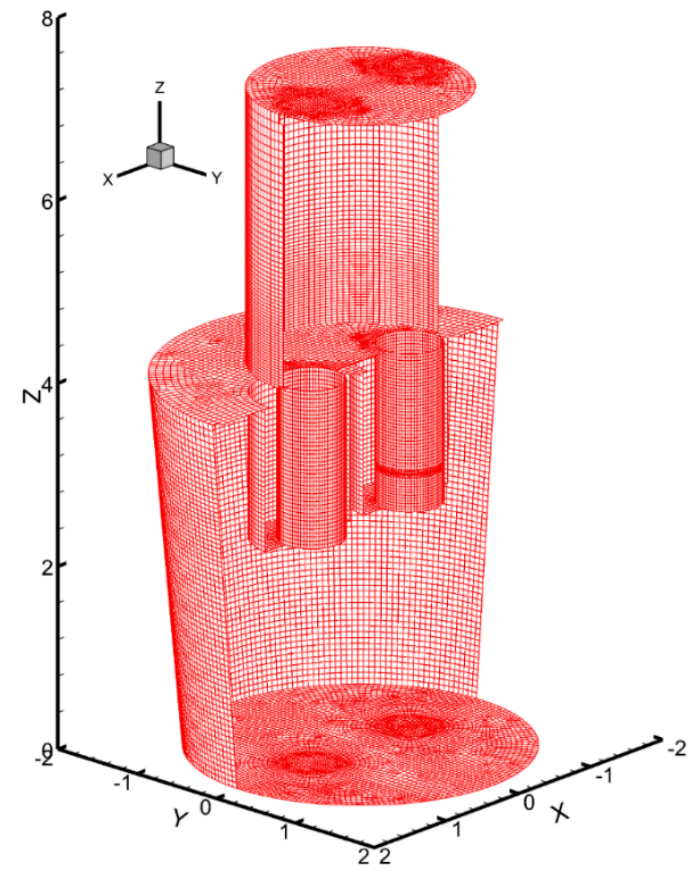

(a)

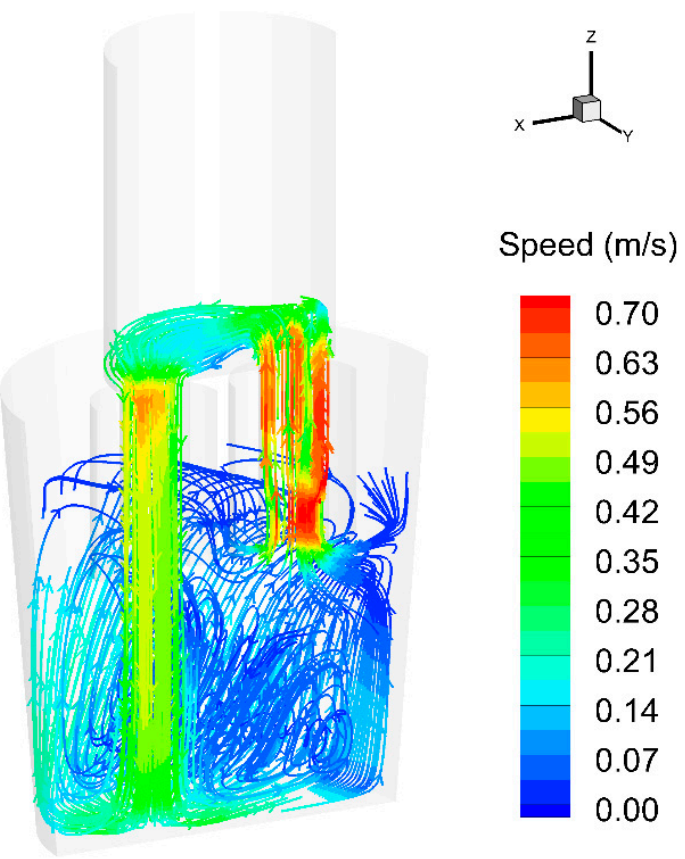

(b)

Figure 1. Fluid flow simulation during RH treatment: (a) Mesh generation; (b) 3D velocity streamlines.

\subsection{Melting of Added Aluminum Particles}

In the refining process of the silicon steel, the cold aluminum is added into the molten steel to control the composition of the molten steel, which is significant to the property of the silicon steel. Figure 2 shows the temperature profile and the melting process of the aluminum particle. Based on the heat transfer between the aluminum particle and the molten steel, the steel shell is frozen around the aluminum particle, and the radius of the particle is given by Equation (1) $[4,23]$.

$$
r=\left\{\begin{array}{cl}
r_{0}\left(1+\frac{2 \sqrt{\mathrm{Fo}}}{\sqrt{\pi} \mathrm{Ph}\left(\rho_{l} / \rho_{A l}\right)}-\frac{\left(\mathrm{Bi \Theta}_{l}+1\right) \mathrm{Fo}}{\operatorname{Ph}\left(\rho_{l} / \rho_{A l}\right)}\right), & \text { Fo }<\frac{1}{\pi} \\
r_{0}\left(1+\frac{1}{2 \operatorname{Ph}\left(\rho_{l} / \rho_{A l}\right)}\left(\frac{1}{\pi}-\mathrm{Bi \Theta} \Theta_{l} \mathrm{Fo}\right)\right), & \text { Fo }>\frac{1}{\pi}
\end{array}\right.
$$


where $r$ is the radius of the particles; $r_{0}$ is the initial radius of the particles; $\rho$ is the density, $\mathrm{kg} / \mathrm{m}^{3}$; and $\Theta_{l}$ is the dimensionless temperature calculated by Equation (2):

$$
\Theta_{l}=\frac{T_{l}-T_{s}}{T_{s}-T_{0}}
$$

where $T_{l}$ is the temperature of molten steel; $T_{S}$ is the solidification temperature of molten steel; $T_{0}$ is the initial temperature of aluminum particles; and $\mathrm{Fo}, \mathrm{Ph}$, and $\mathrm{Bi}$ are dimensionless numbers calculated by the following Equations (3)-(5):

$$
\begin{gathered}
\mathrm{Fo}=\frac{k_{A l} t^{2}}{\rho_{A l} C_{p, A l} r_{A l}^{2}} \\
\mathrm{Ph}=\frac{\Delta H_{s}}{C_{p, A l}\left(T_{s}-T_{0}\right)} \\
\mathrm{Bi}=\frac{\mathrm{Nu} k_{l}}{2 k_{A l}}
\end{gathered}
$$

where $k$ is the thermal conductivity; $t$ is the time; $C_{p}$ is the heat capacity; $\Delta H_{S}$ is the enthalpy change of melting; and $\mathrm{Nu}$ is the Nusselt number calculated by Equation (6), which is related to the Reynolds number Re and the Prandtl number Pr, as follows:

$$
\begin{gathered}
\mathrm{Nu}=2+\left(0.4 \operatorname{Re}^{1 / 2}+0.06 \operatorname{Re}^{2 / 3}\right) \operatorname{Pr}^{0.04} \\
\operatorname{Re}=\frac{2 \rho_{l} r_{A l}\left(u_{l}-u_{A l}\right)}{\mu_{l}} \\
\operatorname{Pr}=\frac{C_{p, l} \mu_{l}}{k_{l}}
\end{gathered}
$$

where $u$ is the velocity; $\mu$ is the viscosity; and the subscripts $l$ and $A l$ represent the liquid steel and the aluminum particle, respectively.

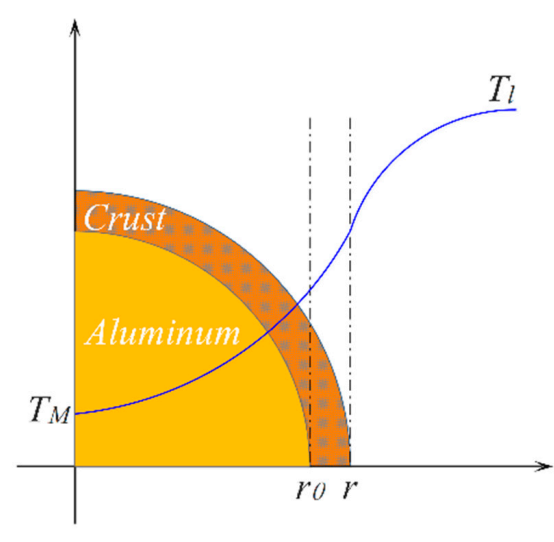

(a)

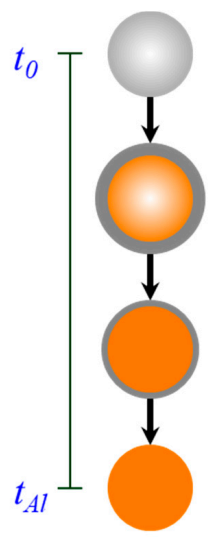

(b)

Figure 2. Schematic of aluminum melting process: (a) Temperature distribution on aluminum particles; (b) Aluminum particles' melting process. ( $T_{m}$ is the temperature of aluminum particles).

Further, the lifetime of the steel shell $t_{A l}$ is derived by Equations (3) and (5) from references [4,23] and given by Equation (9).

$$
\begin{gathered}
t_{A l}=\frac{\rho_{A l} C_{p, A l} r_{A l}}{\pi h \Theta_{l}} \\
h=\frac{N u k_{l}}{2 r_{A l}}
\end{gathered}
$$


where $h$ is the heat transfer coefficient, $\mathrm{J} / \mathrm{m}^{2} \cdot \mathrm{s} \cdot \mathrm{K}$. The material properties and parameters used in the current model are listed in Table 1. In the current work, the liquidus temperature of the molten steel is $1777 \mathrm{~K}$. The actual temperature of the molten steel is higher than its liquidus temperature, and the superheat is the difference between the two temperature values. Four cases with varied superheats are compared in the following part of this paper.

Table 1. Material properties and operation parameters (data from [24]).

\begin{tabular}{cccc}
\hline Item & Symbol & Values & Unit \\
\hline Density of molten steel & $\rho_{l}$ & 7020 & $\mathrm{~kg} / \mathrm{m}^{3}$ \\
Viscosity of molten steel & $\mu_{l}$ & 0.0067 & $\mathrm{~Pa} \cdot \mathrm{s}$ \\
Heat capacity of liquid steel & $C_{p, M}$ & 820 & $\mathrm{~J} /(\mathrm{kg} \cdot \mathrm{K})$ \\
Thermal conductivity of liquid steel & $k_{l}$ & 40.3 & $\mathrm{~J} /(\mathrm{m} \cdot \mathrm{s} \cdot \mathrm{K})$ \\
Solidification temperature of molten steel & $T_{s}$ & 1777 & $\mathrm{~K}$ \\
Initial temperature of aluminum particles & $T_{0}$ & 298 & $\mathrm{~K}$ \\
Density of solidified aluminum & $\rho_{A l}$ & 2700 & $\mathrm{~kg} / \mathrm{m}^{3}$ \\
Heat capacity of aluminum & $C_{p, A l}$ & 1080 & $\mathrm{~J} /(\mathrm{kg} \cdot \mathrm{K})$ \\
Thermal conductivity of aluminum & $K_{A l}$ & 123 & $\mathrm{~J} /(\mathrm{m} \cdot \mathrm{s} \cdot \mathrm{K})$ \\
Enthalpy change of melting of aluminum & $H_{S}$ & $3.88 \times 10^{5}$ & $\mathrm{~J} / \mathrm{kg}$ \\
Argon gas flow rate & $G$ & 1800 & $\mathrm{NL} / \mathrm{min}$ \\
Immersed depth & $H$ & 600 & $\mathrm{~mm}$ \\
Initial radius of aluminum particles & $r_{0}$ & 0.01 & $\mathrm{~m}$ \\
Total mass of added aluminum particles & $m_{A l}$ & 102 & $\mathrm{~kg}$ \\
Temperature of molten steel & $T_{l}$ & $1787 / 1797 / 1805 / 1837$ & $\mathrm{~K}$ \\
\hline
\end{tabular}

When the calculating time exceeds the existence time of the aluminum particles or the calculated particle diameter is smaller than the initial one, it means that the aluminum particle is dissolved into the molten steel and the transport equation is solved by Equation (11):

$$
\frac{\partial}{\partial t}\left(\rho_{l} C_{[A l]}\right)+\nabla \cdot\left(\rho_{l} \vec{u}_{l} C_{[A l]}\right)=\nabla \cdot\left(\frac{\mu_{t}}{S c_{t}} \nabla C_{[A l]}\right)+S_{[A l]}
$$

where $C_{[A l]}$ is the concentration of dissolved aluminum, $S c_{t}$ is the turbulent Schmidt number, and $S_{[A l]}$ is the source item produced by the melting of solid aluminum particles. The mixing time is defined as the first time when the aluminum concentration stabilizes within $\pm 5 \%$. Some variables, including the melting time, the trajectory length, and the melting position, are recorded during the calculation using user-defined functions.

\subsection{Computational Conditions}

In the current work, combined with user-defined subroutines, the model of the aluminum melting process is built by Fluent 17.0, a Computational Fluid Dynamic (CFD) software developed by the FLUENT Inc. company in New York, USA. Based on the steady fluid flow, a certain amount of $10 \mathrm{~mm}$ aluminum particles are added at the center of the vacuum chamber and above the top surface within $1 \mathrm{~s}$. All of the injected particles are randomly distributed within a cube $(0.2 \mathrm{~m} \times 0.2 \mathrm{~m} \times 0.2 \mathrm{~m})$. The convergence criterion is set to be $10^{-6}$ and the time step for the aluminum melting process calculation is $0.01 \mathrm{~s}$. All computations are performed on a Windows 10 personal computer with Intel 3.4GHz CPU and 16GB RAM.

\section{Aluminum Particles Evolution}

\subsection{Melting Process}

Based on an actual industrial experiment, the melting process of aluminum particles is simulated, and the evolution of particles is shown in Figure 3. At the beginning, the added aluminum particles fall into the molten steel with a free-fall velocity. The aluminum particles immerse in the molten steel 
and then quickly float up to the top surface due to the density difference, as shown in the first picture $(t=1 \mathrm{~s})$ in Figure 3. With the fluid flow in the RH reactor, the aluminum particle is spread on the gas-liquid phase interface and moved from the center to the sidewall near the down-leg snorkel. Most of the particles are melted before they reach the sidewall of the vacuum chamber under the superheat of $28 \mathrm{~K}$. The movement of the dissolved aluminum is influenced by the turbulent flow and diffusion.

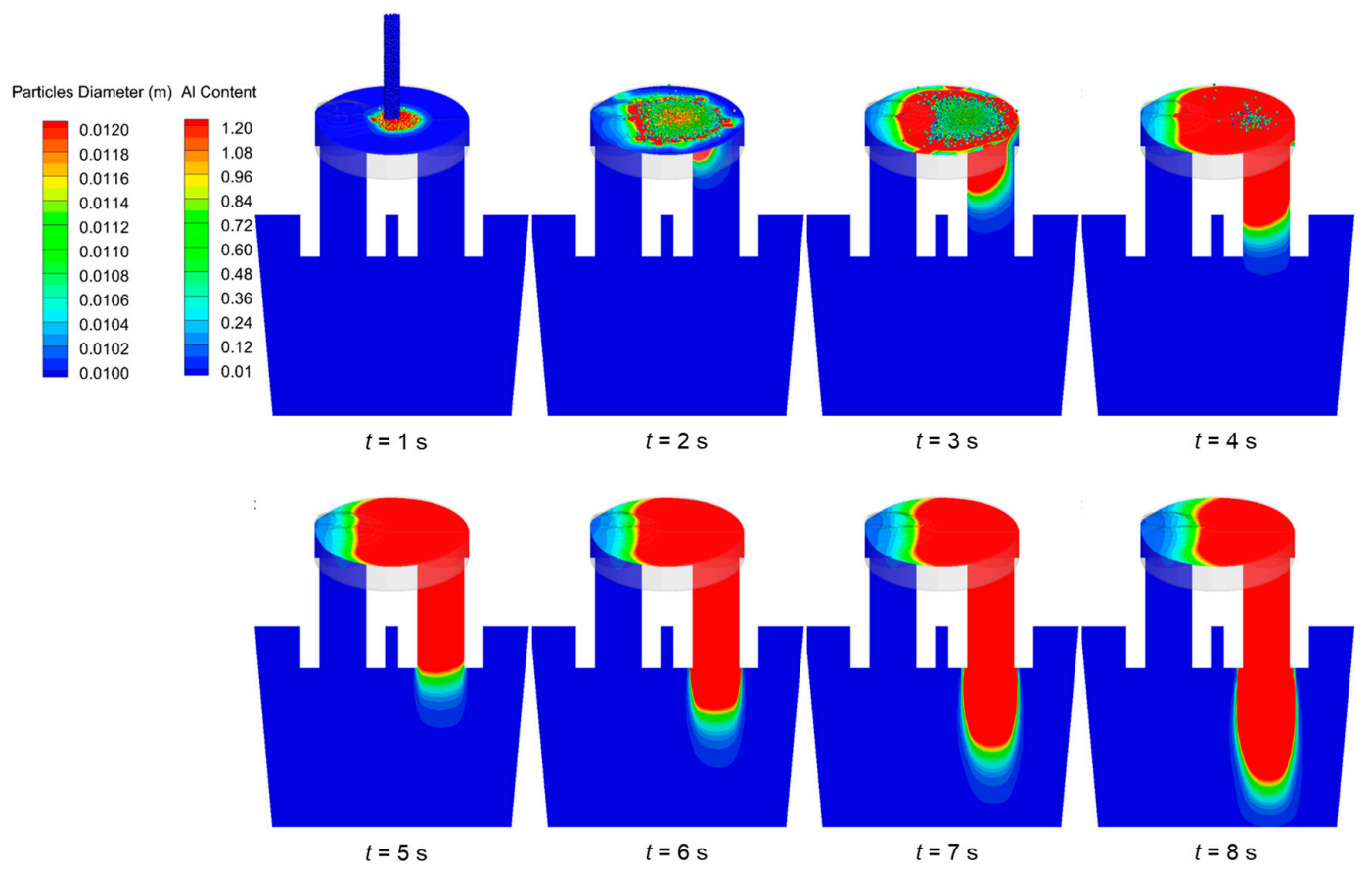

Figure 3. Evolution of added aluminum particles and dissolved aluminum in molten steel.

\subsection{Melting Time and Trajectory Length}

Figure 4 shows the statistical result of the melting time and the trajectory length using the bin size of $0.5 \mathrm{~s}$ and $0.5 \mathrm{~m}$. Due to the high temperature of the molten steel, the added aluminum particles are melted very rapidly. Almost all aluminum particles are melted within $5 \mathrm{~s}$ and most of them are melted at 2.5-3 s after they connect with the molten steel under the condition of $28 \mathrm{~K}$ superheat. The average melting time and the average trajectory length are $2.64 \mathrm{~s}$ and $1.57 \mathrm{~m}$, respectively. The frequency distribution profiles of the melting time and the trajectory length are similar, and both of the two are normal-distributions. The fitting line between the trajectory length and the melting time, $L=0.582 \times t$, as shown in Figure 4, indicates that the average moving velocity of aluminum particles is $0.582 \mathrm{~m} / \mathrm{s}$.

In practice, samples are taken near the point-2(P2) in Figure 5. During the whole RH refining process, chemical compositions of the molten steel change with the time and position. The sampling position may affect the final result and the mixing time is related to the sampling position. Usually, we prefer to take samples at the position with a short mixing time, whose result is close to the average content in the whole ladle. Based on the mixing time, the optimal sampling position can be obtained. The normalized concentration variation of the points with different heights and positions is compared as shown in Figure 6. The peak value for each point increased as the monitor depth increased, and that of the point-3(P3) is the largest. It is suggested that when a shallow sampling position is applied, such as $100 \mathrm{~mm}$ below the top surface in the ladle, the sampling position should be close to the ladle sidewall and away from the two snorkels; when a deep sampling position is applied, such as $500 \mathrm{~mm}$ below the top surface in the ladle, the sampling position should be close to the center between the ladle sidewall and the two snorkels. Anyway, the sampling position in the middle of the two snorkels is inadvisable. From the concentration variation curves, the last point is found outside the range 0.95-1.05, and the corresponding time is defined as the mixing time of this point. The most reasonable sampling position is point-8(P8), which has the shortest mixing time among the nine monitors, as 
shown in Table 2. For 3-4 min after the aluminum addition, the sampling result taken between the snorkels and the ladle sidewall could be used to represent the average result in the $\mathrm{RH}$ reactor.

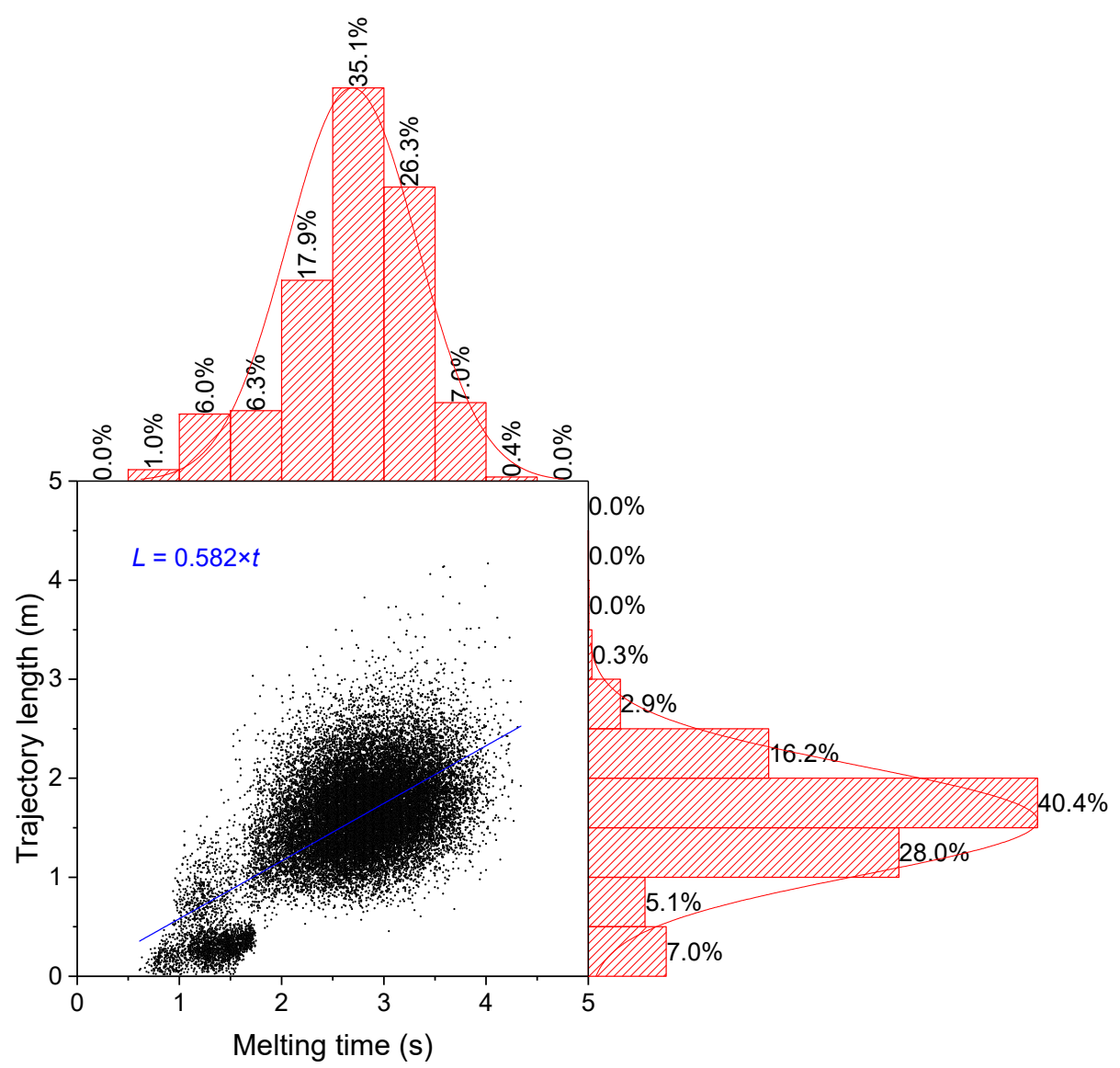

Figure 4. Melting time and trajectory length of aluminum particles.

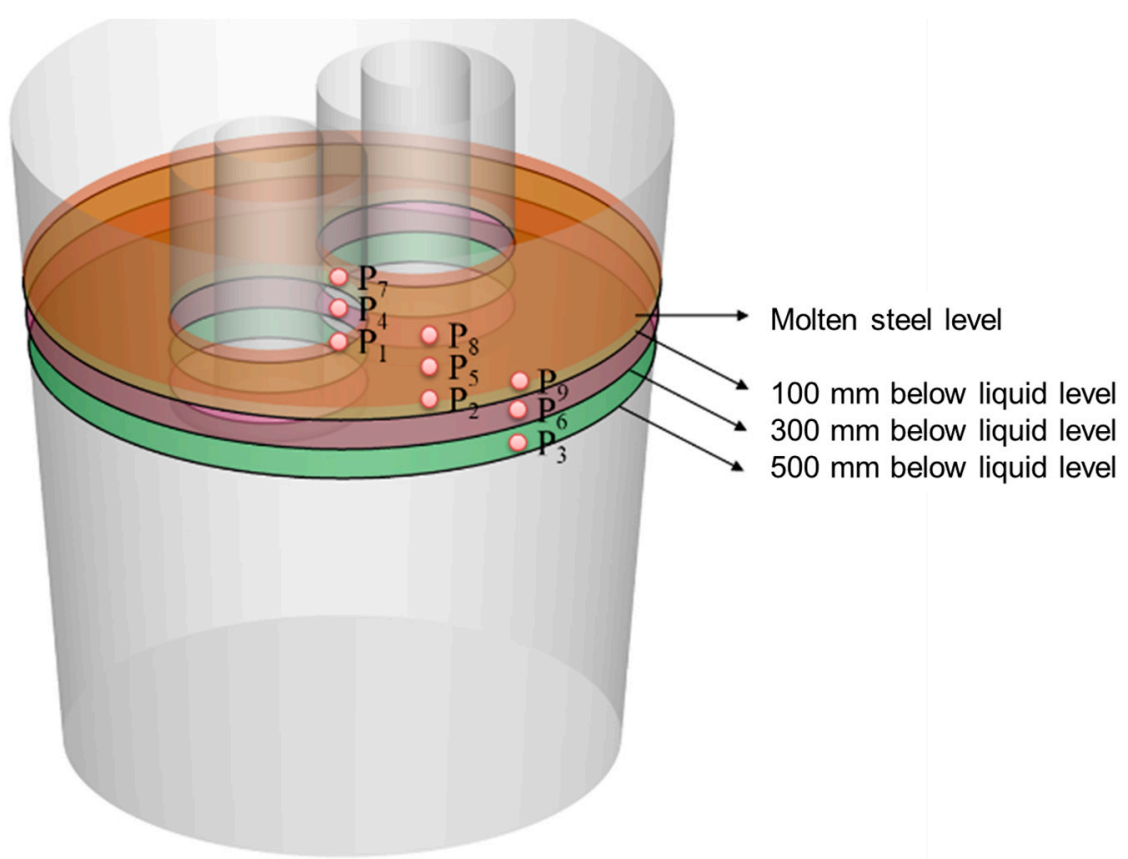

Figure 5. Positions of nine monitors. 


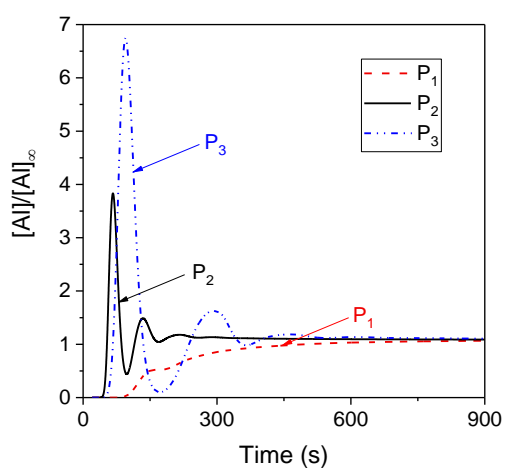

(a)

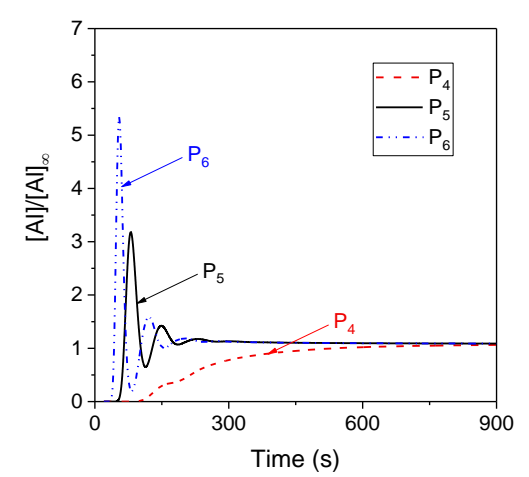

(b)

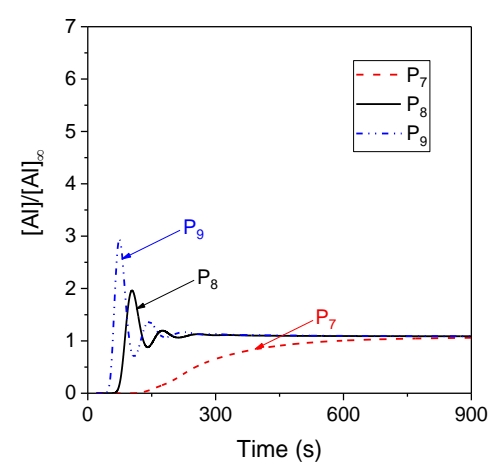

(c)

Figure 6. Variation of the dimensionless concentration of aluminum at three typical monitors: (a) monitors $500 \mathrm{~mm}$ below top surface; (b) monitors $300 \mathrm{~mm}$ below top surface; (c) monitors $100 \mathrm{~mm}$ below top surface.

Table 2. Mixing time results for different monitors.

\begin{tabular}{cccccccccc}
\hline \multirow{2}{*}{ Positions } & \multicolumn{3}{c}{$\mathbf{5 0 0} \mathbf{~ m m}$ below Top Surface } & \multicolumn{3}{c}{$\mathbf{3 0 0} \mathbf{~ m m}$ below Top Surface } & \multicolumn{3}{c}{$\mathbf{1 0 0} \mathbf{~ m m}$ below Top Surface } \\
\cline { 2 - 10 } & $\mathbf{P}_{\mathbf{1}}$ & $\mathbf{P}_{\mathbf{2}}$ & $\mathbf{P}_{\mathbf{3}}$ & $\mathbf{P}_{\mathbf{4}}$ & $\mathbf{P}_{\mathbf{5}}$ & $\mathbf{P}_{\mathbf{6}}$ & $\mathbf{P}_{\mathbf{7}}$ & $\mathbf{P}_{\mathbf{8}}$ & $\mathbf{P}_{\mathbf{9}}$ \\
\hline $\begin{array}{c}\text { Mixing } \\
\text { time (s) }\end{array}$ & 579.7 & 201 & 225.5 & 624.5 & 240.1 & 211.1 & 672.5 & 173.7 & 232.8 \\
\hline
\end{tabular}

\subsection{Model Validation}

The variation of the calculated dissolved aluminum concentration is shown in Figure 7 . The molten steel circulates among the ladle and the vacuum chamber. The dissolved aluminum circulates with the molten steel three times and then gradually reaches full mixing. The tendency of the aluminum content transformation suggests that the calculated results show a good agreement with the measured results. In addition, compared with the results of the industrial experiment, the computational aluminum content is slightly larger than the measured results, which may result from the fact that the current model does not consider the aluminum loss of reactions in the molten steel. Since the reaction of the slag-steel-refractory-inclusions-alloy system is complex, it still needs more concern and further studies.

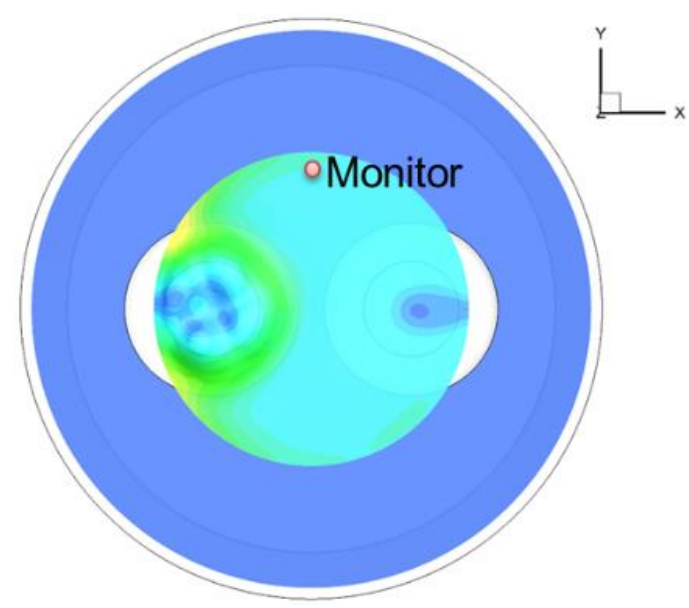

(a)

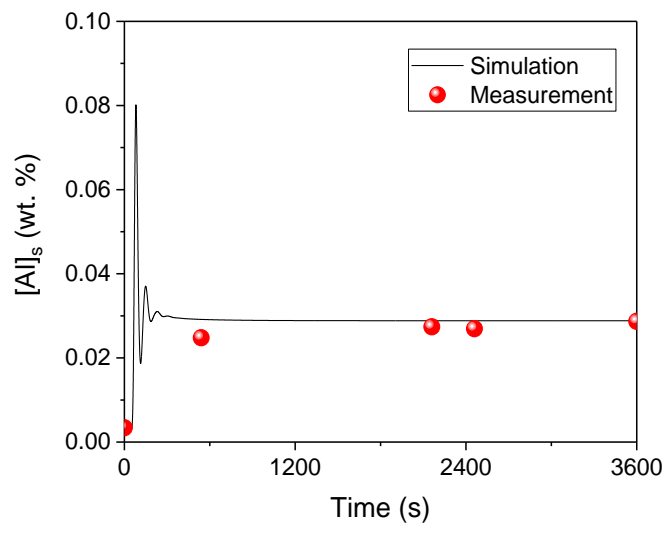

(b)

Figure 7. Comparison of measured and calculated dissolved aluminum in molten steel: (a) Sampling position; (b) model validation. 


\section{Effect of Superheat on the Melting Process}

\subsection{Melting Time and Trajectory Length}

Figure 8 shows the melting process of aluminum particles under different superheat conditions. The solid aluminum particles' melting rate increases when the superheat is increasing. At the time of $6 \mathrm{~s}$, a larger number of aluminum particles exist in the molten steel in Figure 8a for the superheat of $10 \mathrm{~K}$, a small number of aluminum particles exist in the molten steel in Figure $8 \mathrm{~b}$ for the superheat of $20 \mathrm{~K}$, and no aluminum particles exist in the molten steel in Figure 8c for the superheat of $60 \mathrm{~K}$. This means that a higher superheat of the molten steel leads to a faster melting rate of aluminum particles.

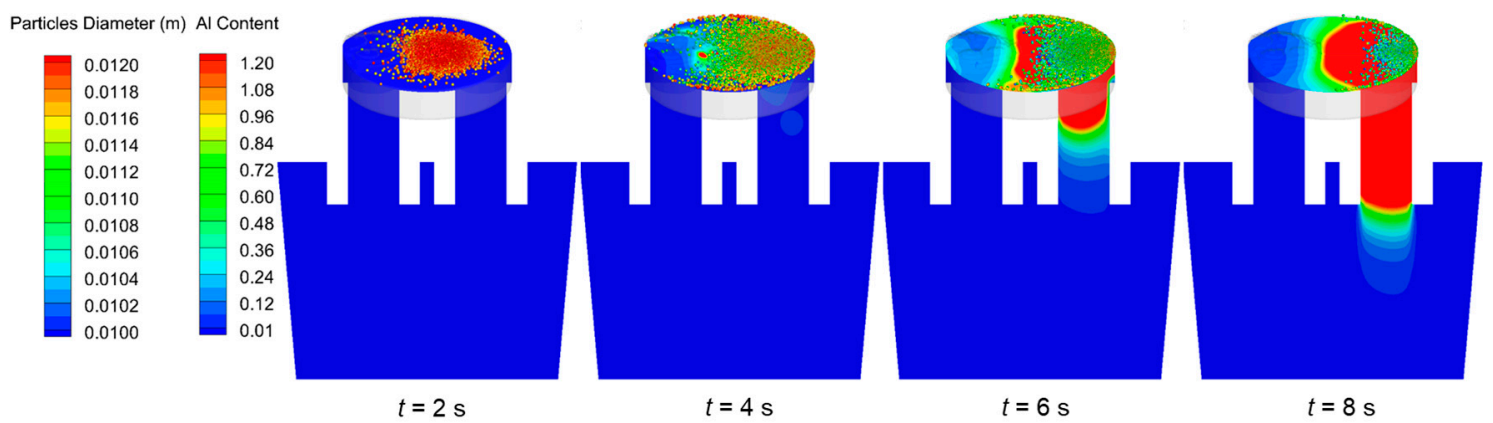

(a)

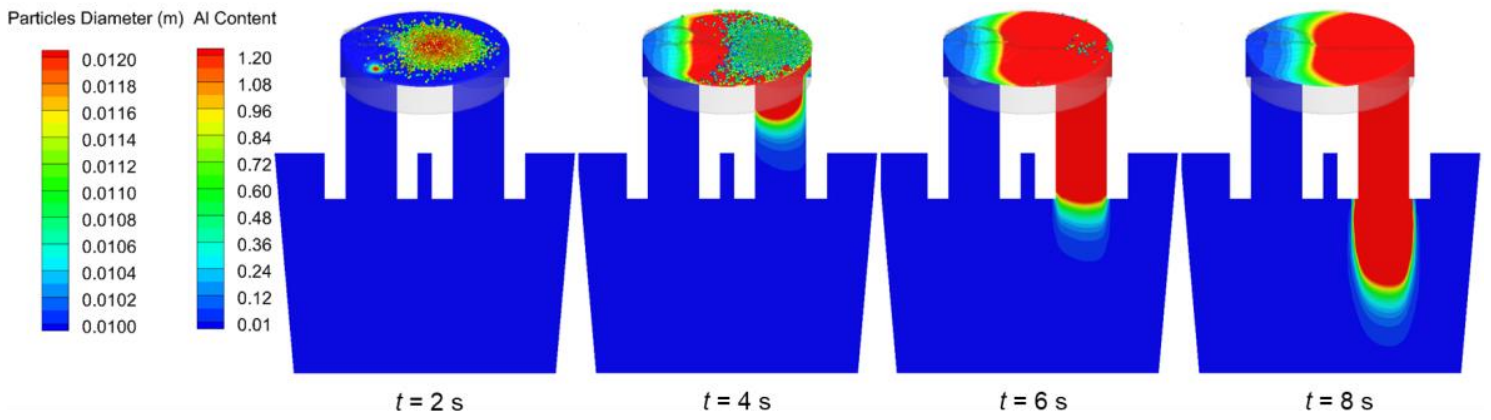

(b)

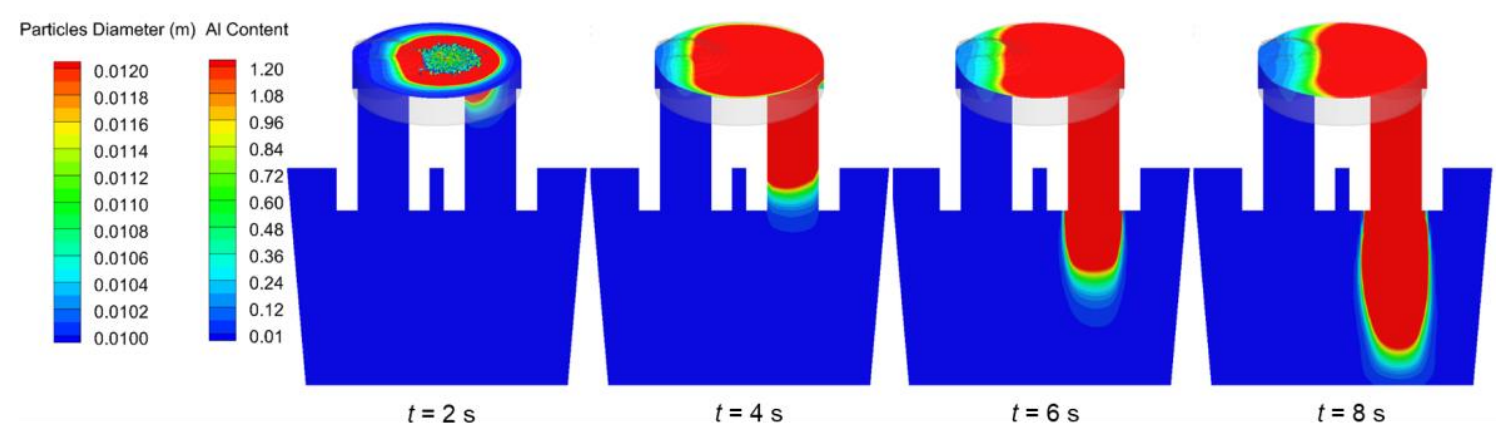

(c)

Figure 8. Aluminum particles' melting process under different superheats: (a) Superheat $=10 \mathrm{~K}$; (b) superheat $=20 \mathrm{~K}$; (c) superheat $=60 \mathrm{~K}$. 
The effect of the superheat values $(10 \mathrm{~K}, 20 \mathrm{~K}$, and $60 \mathrm{~K})$ on the distributions of the melting time and the trajectory length of the added aluminum particles are shown in Figure 9. Both the melting time distribution and the trajectory length distribution show a similar normal distribution. The width of the normal distribution curve decreases and the height of the normal distribution increases as the superheat increases.

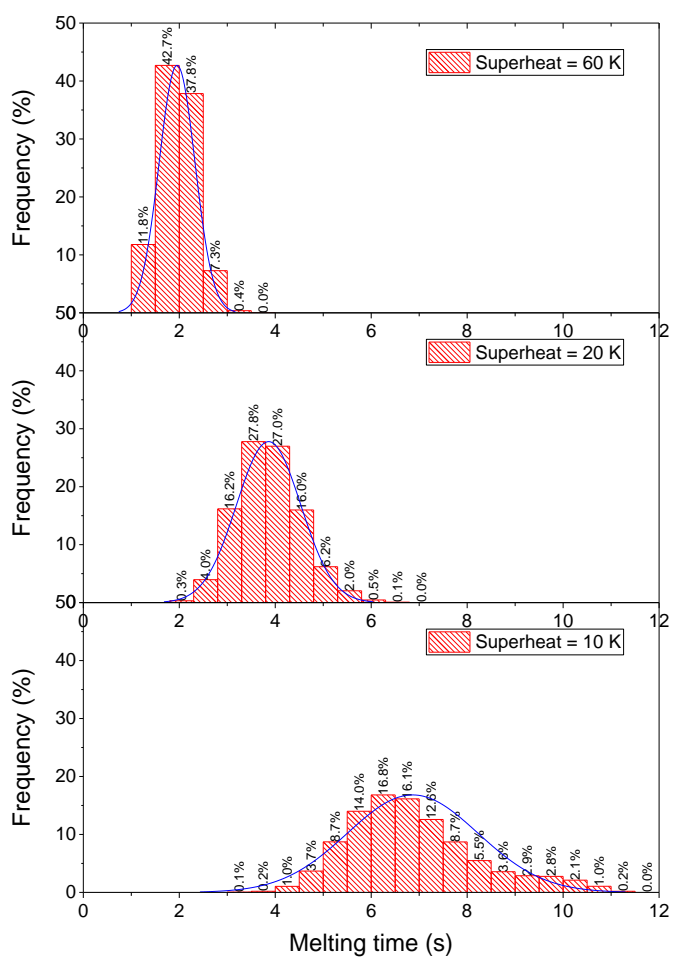

(a)

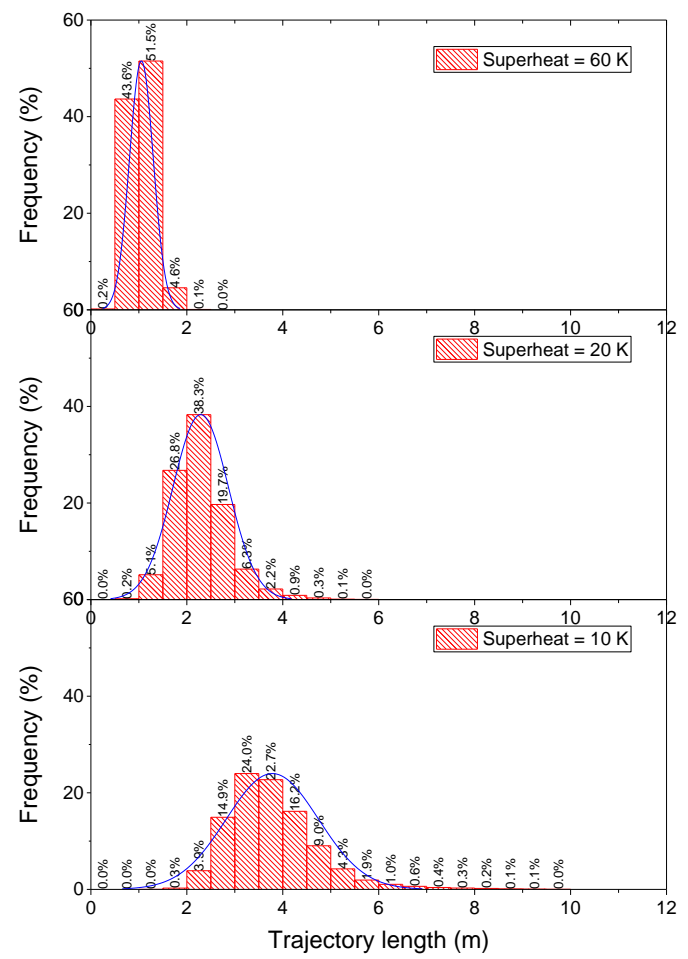

(b)

Figure 9. Melting time and trajectory length of aluminum particles under different superheats: (a) Melting time; (b) trajectory length.

To investigate the effect of the superheat on the melting process, four cases with different superheat values $(10 \mathrm{~K}, 20 \mathrm{~K}, 28 \mathrm{~K}$, and $60 \mathrm{~K})$ are performed, as shown in Figure 10 . Both the melting time and the trajectory length of aluminum particles decrease as the superheat is increasing. When the superheat is more than $28 \mathrm{~K}$, the decreasing rates of the melting time and the trajectory length become slower than those of the superheat lower than $28 \mathrm{~K}$.

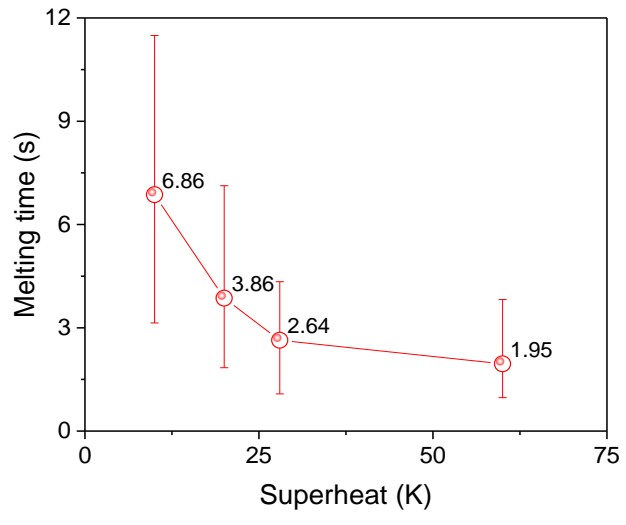

(a)

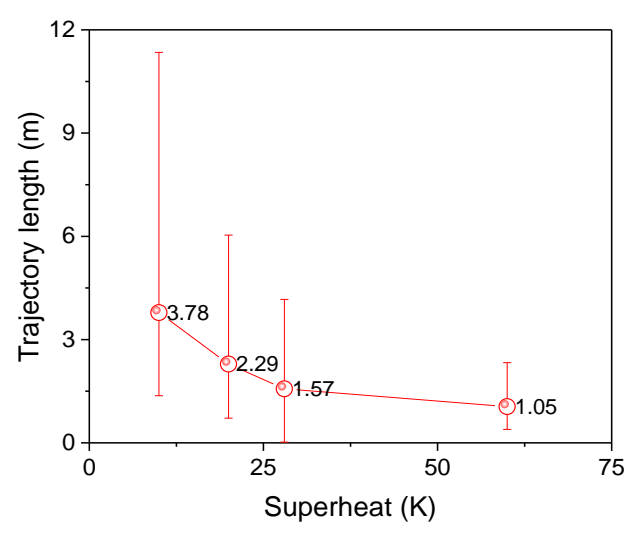

(b)

Figure 10. Effect of superheat on the melting time and the trajectory length of aluminum particles: (a) Melting time; (b) trajectory length. 
Figure 11 shows the variation of the average diameter of present aluminum particles with time. The initial diameter of the aluminum particle is $10 \mathrm{~mm}$. The average diameter of aluminum particles increases first and then decreases as the time is increasing, which revealed the growth and the melting process of the steel crust around the aluminum particle. For the cases with the superheat of $28 \mathrm{~K}$ and $60 \mathrm{~K}$, all of the particles are melted and dissolved into the molten steel within $5 \mathrm{~s}$, while the average diameter decreases very slowly after $5 \mathrm{~s}$ when the superheat is $10 \mathrm{~K}$.

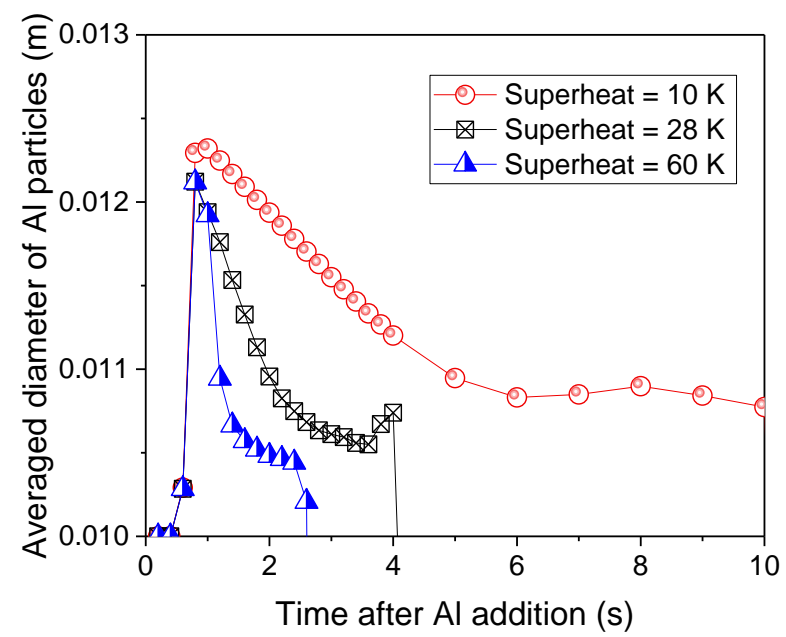

Figure 11. Variation of average aluminum particles diameter with time.

All aluminum particles are melted within a short time, while the melting position for each particle is random. To evaluate the melting position of aluminum particles, the top surface in the vacuum chamber is divided into 2000 cells. The statistics number and probability of aluminum particles melted in each cell are calculated, as shown in Figure 12. For different superheat values, the melting positions of aluminum particles are different. The melting center moves from the sidewall to the center of the vacuum chamber as the superheat is increasing. Additionally, Figure 12 shows that the melting center is close to the down-leg snorkel center with the superheat of $20 \mathrm{~K}$.
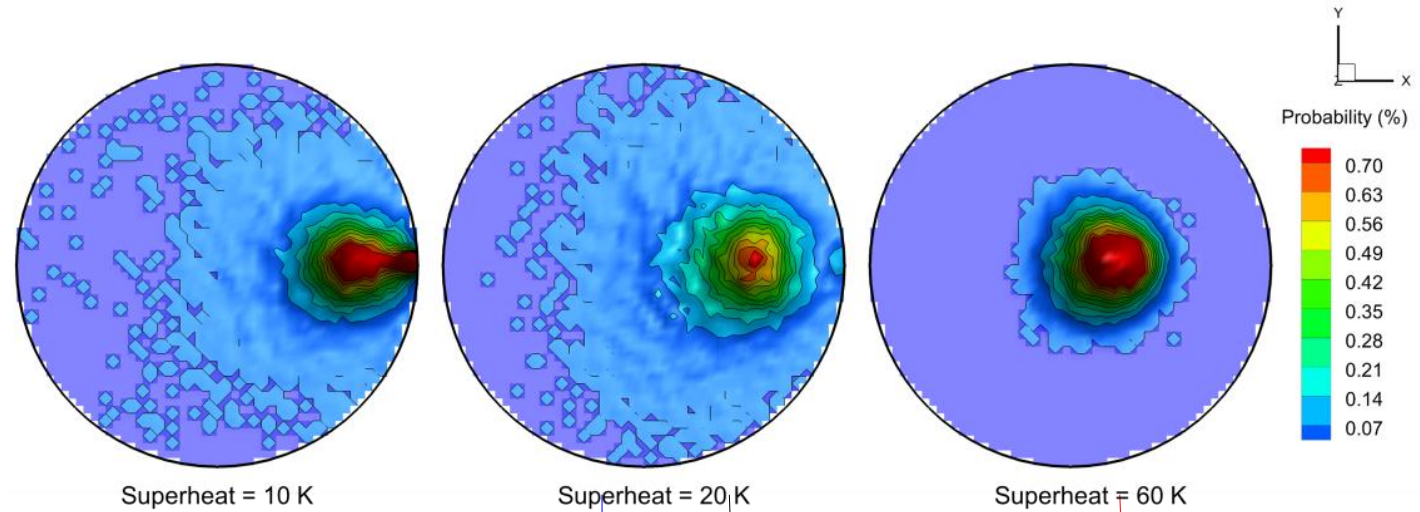

Figure 12. Effect of superheat on the melting position of aluminum particles.

\subsection{Mixing Time}

As shown in Figure 13, the mixing time distributions on the vertical center plane for different superheat values are similar, and it is obvious that the mixing time at the down-leg snorkel exit is less than that at the up-leg snorkel entrance. There is an eddy center near the bottom of the ladle, whose mixing time is less than that of neighboring regions. The comparison shows that the maximum mixing time appeared near the top surface in the ladle, especially between the dawn-leg snorkel and the ladle sidewall, where the flow field is weak. 

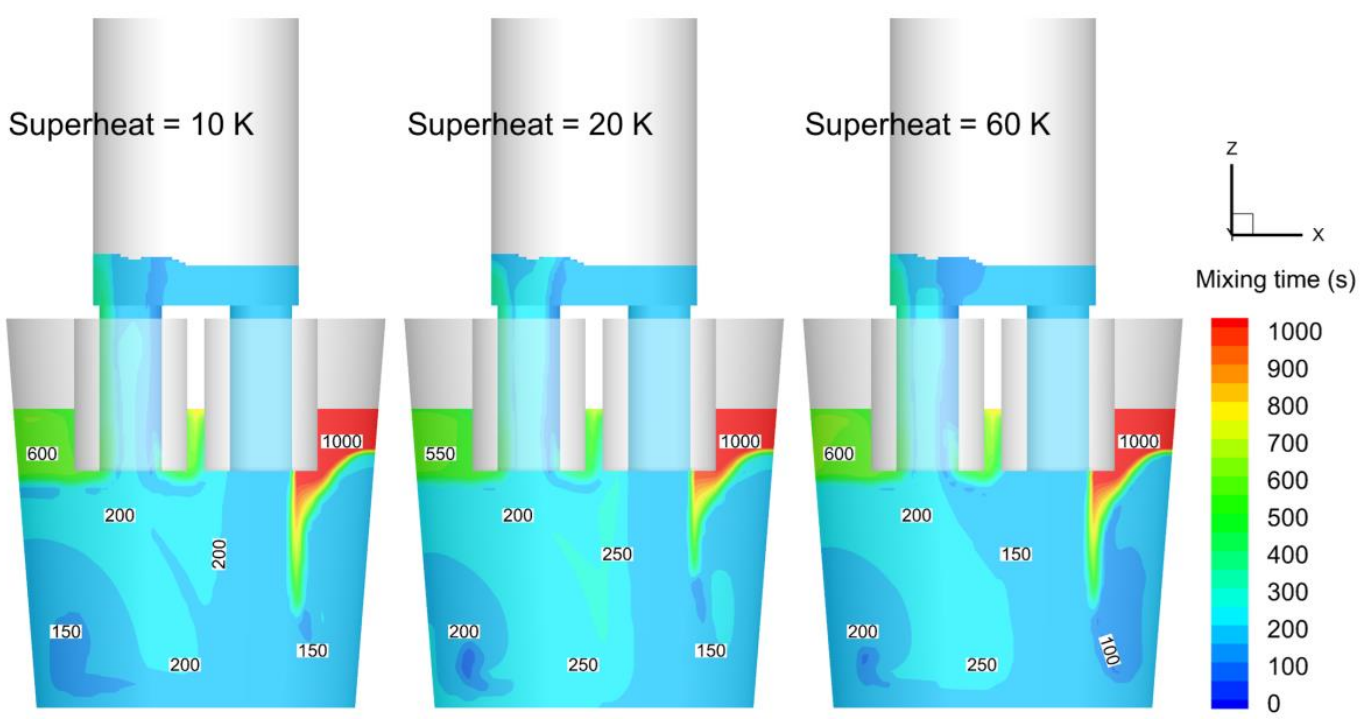

Figure 13. Effect of superheat on the distribution of alloy mixing time.

Figure 14 shows the relationship between the superheat and the maximum mixing time value in the whole computational domain. If the superheat is too low or too high, the mixing time goes up. Since the trajectory length is affected by the superheat, the melting center moves towards the sidewall as the superheat is decreasing. Actually, only when the melting center is close to the center of the down-leg snorkel can an optimized mixing time of the whole ladle be obtained. Thus, when the drop point of added aluminum particles is at the center of the vacuum chamber, the suggested superheat is 20-30 K, which leads to a short time for the complete mixing of added alloy in the molten steel.

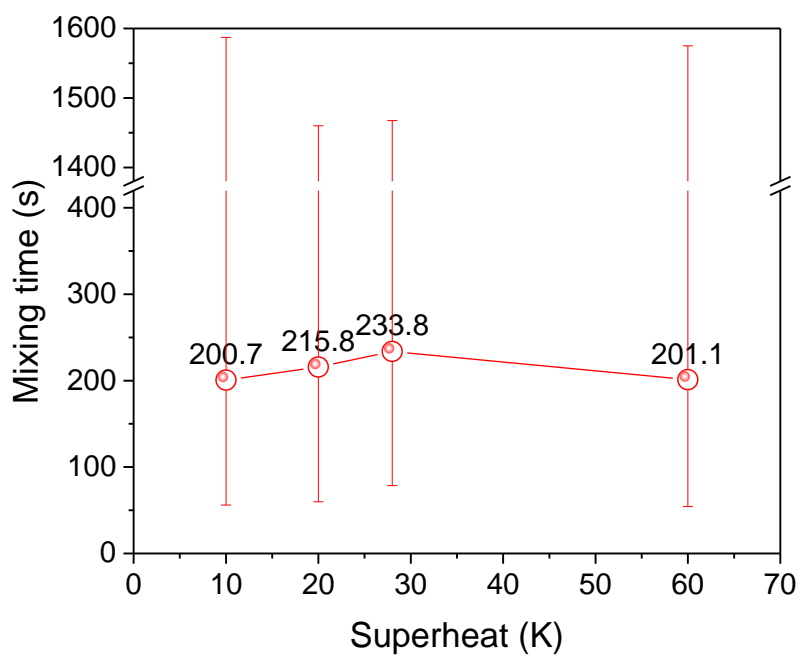

Figure 14. Effect of superheat on the maximum alloy mixing time.

\section{Conclusions}

Coupled with the multiphase fluid flow and the heat transfer, an alloy melting mathematical model is established to investigate the evolution of aluminum particles and the mixing phenomena during the RH refining process. The effect of the superheat on the melting process is discussed and the following conclusions can be drawn:

1. The optimized sampling position is close to the ladle sidewall and away from the two snorkels. The suitable sampling depth is $100 \mathrm{~mm}$ below the top surface in the ladle; 
2. The higher superheat would lead to a short time for the melting of aluminum particles. The decreasing rate of the melting time and the trajectory length would become low if the superheat is over $28 \mathrm{~K}$;

3. The most difficult mixing region, between the down-leg snorkel and the ladle sidewall, is observed. In that region, the mixing time is much higher than that in the interior region away from the two snorkels;

4. The alloy mixing time is influenced by the molten steel temperature. As the added aluminum particles drop at the center of the vacuum chamber, the suitable superheat is $20-30 \mathrm{~K}$ and the mixing time can be reduced.

Author Contributions: Conceptualization, L.Z. and C.L.; methodology, C.L. and H.D.; writing-original draft preparation, C.L.; writing - review and editing, L.Z.

Funding: This research was funded by the National Science Foundation China (Grant No. U1860206, No. 51725402, No. 51504020 and No. 51704018).

Acknowledgments: The authors are grateful for support from the Beijing Key Laboratory of Green Recycling and Extraction of Metals (GREM) and the High Quality Steel Consortium (HQSC) and Green Process Metallurgy and Modeling $\left(\mathrm{GPM}^{2}\right)$ at the School of Metallurgical and Ecological Engineering at University of Science and Technology Beijing (USTB), China.

Conflicts of Interest: The authors declare no conflict of interest.

\section{References}

1. Maas, H.; Hupfer, P. The Significance of the Circulation Rate on the Vacuum Treatment of Liquid Steel with the RH Process. Vacuum 1969, 19, 199-203. [CrossRef]

2. Zhang, L.; Li, F. Investigation on the Fluid Flow and Mixing Phenomena in a Ruhrstahl-Heraeus (RH) Steel Segasser Using Physical Modeling. JOM 2014, 66, 1227-1240. [CrossRef]

3. Wei, J.; Yu, N.; Fan, Y.; Yang, S.; Ma, J.; Zhu, D. Study on Flow and Mixing Characteristics of Molten Steel in RH and RH -KTB Refining Processes. Adv. Manuf. 2002, 6, 167-175. [CrossRef]

4. Zhang, L. Modelling on Melting of Sponge Iron Particles in Iron-Bath. Steel Res. 1996, 67, 466-473. [CrossRef]

5. Zhang, L.; Oeters, F. Mathematical Modelling of Alloy Melting in Steel Melts. Steel Res. 1999, 70, 128-134. [CrossRef]

6. Liuyi, Z.; Franz, O. Melting and Dissolution of High-Melting Alloys in Steel Melts. Steel Res. 2000, 71, $141-144$.

7. Franz, O.; Liuyi, Z.; Christian, H.; Jürgen, L. Laboratory Experiments and Process Modelling of the Melting and Dissolution of Low-Density Ferro-Molybdenum in Steel Melts. Steel Res. 2000, 71, 381-390.

8. Sanyal, S.; Chandra, S.; Kumar, S.; ROY, G.G. An Improved Model of Cored Wire Injection in Steel Melts. ISIJ Int. 2007, 44, 1157-1166. [CrossRef]

9. Taniguchi, S.; Ohmi, M.; Ishiura, S. A hot Model Study on the Effect of Gas Injection Upon the Melting Rate of Solid sphere in A Liquid Bath. Trans. Iron Steel Inst. Jpn. 2006, 23, 571-577. [CrossRef]

10. Guthrie, R.; Gourtsoyannis, L.; Henein, H. An Experimental and Mathematical Evaluation of Shooting Methods for Projecting Buoyant Alloy Additions into Liquid Steel Baths. Can. Metall. Q. 1976, 15, 145-153. [CrossRef]

11. Aoki, J.; Thomas, B.G.; Peter, J.; Peaslee, K.D. Experimental and Theoretical Investigation of Mixing in A Bottom Gas-Stirred Ladle. AISTech 2004, 1, 1045-1056.

12. Silva, C.A.D.; Silva, I.A.D.; Martins, E.M.D.C.; Seshadri, V.; Perim, C.A.; Filho, G.A.V. Fluid Flow and Mixing Characteristics in RH Degasser of Companhia Siderúrgica de Tubarão, and Influence of Bottom Gas Injection and Nozzle Blockage through Physical Modelling Study. Ironmak. Steelmak. 2004, 31, 37-42. [CrossRef]

13. Tsujino, R.; Nakashima, J.; Hirai, M.; Sawada, I. Numerical Analysis of Molten Steel Flow in Ladle of rh Process. ISIJ Int. 1989, 29, 589-595. [CrossRef]

14. Park, Y.; Doo, W.; Yi, K.; An, S. Numerical Calculation of Claircution Flow Rate in the Degassing Rheinstahl-Heraeus Process. ISIJ Int. 2000, 40, 749-755. [CrossRef]

15. Kuwabara, T.; Umezawa, K.; Mori, K.; Watanabe, H. Investigation of Decarburization Behavior in RH-Reactor and its Operation Improvement. Trans. Iron Steel Inst. Jpn. 1988, 28, 305-314. [CrossRef] 
16. Inoue, S.; Furuno, Y.; Usui, T.; Miyahara, S. Acceleration of Decarburization in RH Vacuum Degassing Process. Trans. Iron Steel Inst. Jpn. 1992, 32, 120-125. [CrossRef]

17. Takahashi, M.; Matsumoto, H.; Saito, T. Mechanism of Decarburization in RH Degasser. Trans. Iron Steel Inst. Jpn. 1995, 35, 1452-1458. [CrossRef]

18. Miki, Y.; Shimada, Y.; Thomas, B.G.; Denissov, A. Model of Inclusion Removal during RH Degassing of Steel. Iron Steelmak. 1997, 24, 31-38.

19. Chen, G.; He, S.; Li, Y.; Wang, Q. Modeling Dynamics of Agglomeration, Transport, and Removal of Al2O3 Clusters in the RH Reactor Based on CFD-PBM Coupled Model. Ind. Eng. Chem. Res. 2016, 55, 7030-7042. [CrossRef]

20. Shirabe, K.; Szekely, J. A Mathematical Model of Fluid Flow and Inclusion Coalescence in the RH vacuum Degassing System. Trans. Iron Steel Inst. Jpn. 1983, 23, 465-474. [CrossRef]

21. Liu, C.; Li, S.; Zhang, L. Simulation of Gas-Liquid Two-Phase Flow and Mixing Phenomena during RH Refining Process. Acta Metall. Sin. 2018, 54, 347-356.

22. Luo, Y.; Liu, C.; Ren, Y.; Zhang, L. Modeling on the Fluid Flow and Mixing Phenomena in a RH Steel Degasser with Oval down-Leg Snorkel. Steel Res. Int. 2018, 89, 1800048. [CrossRef]

23. Zhang, L.; Jing, X.; Jiying, L.I.; Thongbo, X.U.; Cai, K. Mathematical Model of Decarburization of Ultra Low Carbon Steel during RH Treatment. Int. J. Miner. Metall. Mater. 1997, 4, 19-23.

24. Gale, W.F.; Totemeier, T.C. Smithells Metals Reference Book; Elsevier Butterworth-Heinemann publications: Oxford, UK, 2004.

(C) 2019 by the authors. Licensee MDPI, Basel, Switzerland. This article is an open access article distributed under the terms and conditions of the Creative Commons Attribution (CC BY) license (http://creativecommons.org/licenses/by/4.0/). 